\title{
The Impact of Task Difficulty and Language Proficiency on Iranian EFL Learners' Code- switching in Writing
}

\author{
Amir Sabzevar Qahfarokhi \\ Department of English, Islamic Azad University, Shahrekord Branch, Shahrekord, Iran \\ Email: amir.sabzevari@yahoo.com \\ Reza Biria \\ Department of English, Khorasgan (Isfahan) branch, Islamic Azad University, Isfahan, Iran
}

\begin{abstract}
This study sought to investigate code-switching in the writing of Iranian EFL learners. Code switching can occur both in spoken and written discourse. In order to measure this behavior in the writing of Iranian EFL learners, a total of 30 participants (15 intermediate and 15 advanced learners) were randomly selected. An Oxford Placement Test was administered to determine their level of second language (L2) proficiency. For gathering the relevant data from the learners, two writing tasks with different levels of difficulty were employed. The participants were required to think aloud as they were engaged in the act of writing. The data gathered from the think-aloud protocols were then analyzed and used for further analysis. Several independent T-test were conducted to analyze the data collected from the think-aloud protocols. The results showed that level of proficiency on the one hand and task level of difficulty were influential factors in writers' rate of switching to their first language (L1).
\end{abstract}

Index Terms - code-switching, think-aloud protocol, L2 proficiency, task difficulty

\section{INTRODUCTION}

Communication strategies are important in helping L2 learners to communicate successfully when they are faced with a problem in speech production. Based on a research done at Mahidole University on the use of communication strategies of students engaging in interviews with native speakers, it was found that learners used strategies like modification devices, non-linguistic strategies, L1-based strategies, target language-based strategies and avoidance strategies. The results showed that students used different strategies with varying degrees according to their language levels. Bialystok (1990) referred to the lack of L2 knowledge as a 'gap'. Communication strategies generally have been defined as "devices employed by L2 learners when they encounter communication problems in L2 communication because their communication ends have outrun their communicative means"( Faerch \& Kasper, 1983).

One of the strategies employed by students was L1- switching which was found the most in the group with low level of oral proficiency. However, the ways in which students switched to their L1 were different. Students with a low level of proficiency used L1 randomly and were unaware that they were using it. Students with high language proficiency usually switch to L1 for exclamation.

In another study conducted on the number of code-switching among Chinese teachers of English it was revealed that, in most cases, code-switching by teachers serves some kind of pedagogical purposes. Code-switching, which may be briefly defined as the alternate use of two or more languages in the same utterance or conversation (Grosjean, 1987; Milroy \& Muysken, 1995) has attracted much scholarly attention in the last decades. As a common occurrence in ESL/EFL teaching/learning process, code-switching can be evidenced along the entire continuum of proficiency (Brice, 2000). Since the researcher intends to address this issue of bilingual performance not from a socio-linguistic or anthropological perspective but rather from a psycholinguistic perspective, the term 'code-switching' will be used to refer to a cognitive phenomenon that is distinct from the code-switching observed by sociolinguists (Woodall, 2000). As such, 'code-switching' here refers to the act of switching from second language (L2) to first language (L1) as the language of thinking in the cognitive process of a bilingual person engaged in an L2 composing task.

\section{REVIEW OF LITERATURE}

The term 'code-switching' (C-S) refers to the phenomenon of using more than one language in a certain situation. (Grosjean, 1987). Code-switching as a term, however, has largely been used in the sociolinguistic domain to refer to the use of more than one language in the course of a single communicative episode (see, Heller, 1988). Code-switching is a phenomenon at the disposal of bilinguals or tri-linguals and this occurs when, in the act of speaking, a speaker switches from one language to the other for some communication reasons. This happens and it is nothing unique to speaking, but 
we can see instances of L-S in L2 writing too. Of course the function may be different from that of in speaking (Qi, 1984).

Silva (1993) conducted empirical research to examine L1 and L2 writing. The subjects involved in his research came from a variety of backgrounds. At least 27 different L1 were represented. The subjects were undergraduate college students in US who were at the advanced levels of English proficiency and exhibited a wide range of levels of writing ability. Silva points out that his research showed that writers, who were asked to perform in L1 and L2, devoted more attention to generating material in L2 than in L1 and found content generation in L2 more difficult and less successful. Much of the materials generated in L2 were not used in the students' written text (Silva 1993). In addition, Silva found that writers did less planning at the global and local levels. Global level means the writer is dealing with the topic area from a variety of perspectives. Local level means the writer is dealing with her syntactic and lexical options in the context of her own written text. According to Silva (1993) L2 writers did less goal setting and had more difficulty organizing generated material (the same writers did not have this problem in L1). In general, adult L2 writing was less effective than L1 writing. In terms of lower level concerns, L2 writing was stylistically different and simpler in structure.

Berman (1994) found in researching 126 secondary school students in Iceland, who were studying English as a foreign language (EFL), that 'many learners transfer their writing skills between languages, and their success in doing so is assisted by the grammatical proficiency in the target language' (Berman p. 29). Berman used an experimental approach where the subjects were divided into three groups and each group either received L1 essay writing instruction or L2 essay writing instruction or no instruction. The pre- and post-test essay organization and grammatical proficiency scores were analyzed. Berman's results indicate learners' transfer of writing skills from their L1 (Icelandic) to L2 (English) and he noticed that the transfer depended on their English grammatical proficiency; Berman cautions that we must be careful not to generalize findings made in the second language context to the foreign language classroom, for example, expecting that transfer of academic skills 'to occur' (Berman p.39).

While writing in the L2, writers switch to their L1 from time to time because of, maybe, some deficiency in their L2 knowledge and proficiency to compensate for this gap in their knowledge. Sometimes this happens because of the cognitive demand of the task, the more demanding the task, the more writers make use of their L1 conversely, the more easier the task, the less the writers switch to their L1. Therefore, switching to one's native language is triggered by two factors: L2 writers' level of proficiency and task level of cognitive demand. All said and done, this is where the problem lies and this is what is going to be investigated in this research.

Evidence from research in this domain has suggested that L1 plays a positive role in almost all the subcategories of the field of L2 composing including L1 knowledge transfer (Edelsky, 1982; Friedlander, 1990); planning skills (Jones \& Tetroe, 1987); heuristic searches in thinking for production (Cumming, 1989); revising (Hull, 1985); translation (Kobayashi \& Rinnert, 1992; Uzawa, 1996); problem-solving in math (Tamamaki, 1993); and the effects of L1 composing expertise on the quality of L2 texts (Cumming, 1989). The results of these studies have strongly indicated not only the effectiveness but also the necessity of language-switching in the thinking processes of L2 composing.

$\mathrm{C}-\mathrm{S}$ in writing may be defined as spontaneous use of the first language during the L2 writing process. The switch occurs sub-vocally (talking to oneself) or what Vygotsky (1978) calls "private speech", a mental operation used to control or regulate difficult mental processes (Anton \& DiCamilla, 1998). According to Cumming, 1989 and Qi, 1998, L-S of the L2 writer is done intra-mentally to compensate for difficulties encountered in using the second language.

One such difficulty faced by EFL learners is the discrepancy between level of L2 proficiency and the difficulty level of writing tasks assigned to learners at different levels of proficiency. The studies mentioned before (Cumming, 1989, 1990; Friedlander, 1990; Johns \& Tetroe, 1987; kobayashi \& Rinnert, 1992; Whalen \& Menard, 1995; Manchon et al., 2000; Zimmerman, 2000) have provided a valuable but partial look at C-S behavior. It is not clear what exactly contributes to $\mathrm{C}-\mathrm{S}$, of the many factors involved, two of them are investigated here:

The effect of L2 proficiency on code-switching,

The effect of task difficulty on code-switching,

\section{RESEARCH QUESTIONS}

Based on what was mentioned above this study therefore, seeks answers to the following questions:

Question 1: Does L2 proficiency level have any effect on the writers' rate of switching to his/her L1?

Question 2: Does task level of difficulty have any effect on writers' rate of switching to his/her L1?

\section{METHOD}

\section{A. Participants}

The participants in this study were 15 intermediate and 15 advanced level EFL students. The students were selected from a language institute, namely, SADR Institute of Higher Education. The text-books which were used were New Interchange series, second edition. There were 12 levels and intermediate students were selected from levels $7 \& 8$, whereas advanced students were selected from level 12. Students were learning English as a foreign language and there was no control for their gender and age since they were of different age groups (mostly young adults). This sample 
population was randomly selected out of a larger population of about 60 students. Students were grouped according to their L2 proficiency which was determined by students' enrollment in English classes, held in language institutes. Because the classification of L2 proficiency may differ from language program to language program and in order to reduce the threats to reliability a second proficiency test (Oxford Proficiency Test) was conducted on the sample group to make sure they are on the right level, namely, intermediate and advanced. According to the proficiency test, subjects scoring under 40 were considered as intermediate students and those scoring above 40 were taken as advanced students.

\section{B. Materials}

The materials for this research consisted of an oxford proficiency test. This test was made up of 50 multiple-choice questions. According to this rest, scores above 40 are considered as advanced level of proficiency and scores under 40 down to 30 are considered as intermediate level of proficiency.

Moreover, two writing tasks were provided, one as the easy task and the other as the difficult task. The tasks were used to elicit and collect the intended data. Two tasks were selected to represent two levels of difficulty to see to what extent the writers switched to their mother tongue whenever they came across any difficulty while writing in their L2 English. The easy task was a personal letter and the difficult task was writing an essay. The tasks proper are not supposed to measure anything but rather they are used as a means to measure the frequency of language switching. The relation between task and switching was that of a reciprocating and one-to-one relation, that is, as the tasks level of difficulty increase the writers were supposed to tend to side step the target language and resort to their L1 and switch more and more.

In addition to what was mentioned above, bilingual dictionaries were provided along with pen and paper. Dictionaries were provided to help the participants look up unknown words. In order to make the subjects relaxed and get them to write and do what they were supposed to do they were put in a conference room to avoid distracters and unwanted noise. As far as the recording was concerned, a Samsung voice recorder with a high quality was used throughout the whole procedure of data collection.

\section{Procedure}

In order to collect C-S data for the analysis, the participants were asked to think aloud while producing two writing samples, a personal letter and a persuasive essay. Although think-aloud protocols have been criticized for causing problems of validity (zamel, 1983) and reliability when carefully conducted they remain useful for obtaining data on writing processes like C-S. To minimize threats to validity, the participants were asked simply to report their thoughts. They were not asked to interpret or filter their thoughts through a secondary process such as "report only those thoughts that are related to the task. To minimize variability due to topic knowledge, the two writing tasks were chosen as texts not requiring any specific knowledge. Furthermore, the tasks were selected to represent two levels of difficulty: the letter being an easier task and the essay the more difficult one. To achieve these levels of difficulty, the writing prompts were created with Bereiter and scardamalia's (1987) dual writing model in mind. Bereiter and Scardamilia defined an easy writing task as one in which the writer was expected to engage in "knowledge telling," and the difficult task as one involving "knowledge transformation." To increase the difference in difficulty between the two tasks, the instructions for them differed in both detail and character. The instructions for the easier letter task included a list of specific, personal information to be included in the text, such as age, gender, hobbies, etc. it was assumed that this information was readily available to working memory, and therefore the task could be easily performed through the knowledgetelling process. Furthermore the instruction for the easier task provided an audience for the text.

The instruction and topic for the more difficult essay writing task were more abstract. The essay task was more likely to involve knowledge transforming because it required the writer to develop a problem space that creates the answer to the question, rather than a memory search that simply recalls the answer.

C-S data, the dependent variable, were defined as any use of the L1 while engaged in the L2 writing process. A switch started with an utterance in the L1 and ended with the next utterance in the L2. The frequency of switches was observed. The measure of frequency simply counted the number of switches. It should be noted that only the verbalized switches were observed and recorded. The measures of $\mathrm{C}-\mathrm{S}$ data were recorded on forms. These forms were allowed to indicate the general writing activity at the time of the Code-switching.

\section{RESUlTS AND DiSCUSSION}

For each participant two samples of writing was collected from the think-aloud protocols: One for the easy (letter) task and another one for the difficult (essay) task. In other words each participant in both advanced and intermediate groups had two results. After analyzing the protocols for the frequency of L1 switches, the following results were obtained:

As for the frequency of switches in both tasks in the intermediate and advanced groups, the number of switches were counted and then four T-tests were conducted as follows: two independent T-tests for both easy and difficult tasks to compute the frequency of switches in the difficult and easy tasks between groups, for instance, the frequency of switches in the difficult tasks between intermediate and advanced groups and the same measurement for the easy tasks between the same two groups. 
An independent-samples t-test was conducted to compare the rate of switching in easy task between the intermediate and advanced groups. Table 1 shows the group statistics for the two groups. Table 2 shows the independent T-test for easy task switches. There was a significance difference for the intermediate group $(\mathrm{M}=12.13, \mathrm{SD}=3.09)$ and the advanced group $(\mathrm{M}=2.27, \mathrm{SD}=1.33)$. According table 2 the observed $\mathrm{T}$ here is 11.351 for the df of 28 corresponding the critical $\mathrm{T}$ value table, the observed $\mathrm{T}$ is significant at all levels. Tobs $=11.351, \mathrm{df}=28, \mathrm{p}<0.001$

TABLE 1.

GROUP STATISTICS

\begin{tabular}{|l|lllll|}
\hline \multirow{3}{*}{ Easy task switches } & Groups & $\mathrm{N}$ & Mean & Std. Deviation & Std. Error Mean \\
\cline { 2 - 7 } & Intermediate & 15 & 12.13 & 3.09 & .80 \\
\cline { 2 - 7 } & Advanced & 15 & 2.27 & 1.33 & .34 \\
\hline
\end{tabular}

TABLE 2.

INDEPENDENT TEST FOR EASY TASK SWITCHES.

\begin{tabular}{|c|c|c|c|c|c|c|c|}
\hline \multirow{5}{*}{ Easy task switches } & $\begin{array}{l}\text { t-test for Equality of } \\
\text { Means }\end{array}$ & \multirow{3}{*}{ df } & \multirow{3}{*}{ Sig. (2-tailed) } & \multirow{3}{*}{ Mean Difference } & \multirow{3}{*}{$\begin{array}{l}\text { Std. Error } \\
\text { Difference }\end{array}$} & \multirow{2}{*}{\multicolumn{2}{|c|}{$\begin{array}{l}95 \% \text { Confidence Interval of the } \\
\text { Difference }\end{array}$}} \\
\hline & \multirow[t]{2}{*}{ P } & & & & & & \\
\hline & & & & & & Lower & Upper \\
\hline & 11.351 & 28 & .000 & 9.87 & .87 & 8.09 & 11.65 \\
\hline & 11.351 & 19.045 & .000 & 9.87 & .87 & 8.05 & 11.69 \\
\hline
\end{tabular}

Another independent T-test was conducted for the switches in the difficult tasks between the two groups. Table 3 shows the group statistics for the rate of switching in difficult task between the intermediate $(\mathrm{M}=22.47, \mathrm{SD}=4.17)$ and advanced group $(\mathrm{M}=5.80, \mathrm{SD}=1.82)$. Table 4 shows the independent T-test for difficult task switches. According to table 4 the $\mathrm{T}$ observed is 14.179 for the df of 28 corresponding the critical $\mathrm{T}$ value table, the observed $\mathrm{T}$ is remarkably significant at all the levels. Tobs $=14.179, \mathrm{df}=28, \mathrm{p}<0.001$

TABLE 3.

GROUP STATISTICS

\begin{tabular}{|llllll|}
\hline \multirow{2}{*}{ Difficult task switches } & Groups & $\mathrm{N}$ & Mean & Std. Deviation & Std. Error Mean \\
\cline { 2 - 7 } & Intermediate & 15 & 22.47 & 4.17 & 1.08 \\
\cline { 2 - 7 } & advanced & 15 & 5.80 & 1.82 & .47 \\
\hline
\end{tabular}

TABLE 4.

INDEPENDENT TEST FOR DIFFICULT TASK SWITCHES.

\begin{tabular}{|c|c|c|c|c|c|c|c|}
\hline \multirow{5}{*}{ Difficult task switches } & $\begin{array}{l}\text { t-test for Equality of } \\
\text { Means }\end{array}$ & \multirow{3}{*}{ df } & \multirow{3}{*}{$\begin{array}{l}\text { Sig. (2- } \\
\text { tailed) }\end{array}$} & \multirow{3}{*}{ Mean Difference } & \multirow{3}{*}{$\begin{array}{l}\text { Std. Error } \\
\text { Difference }\end{array}$} & \multirow{2}{*}{\multicolumn{2}{|c|}{$\begin{array}{l}95 \% \text { Confidence Interval of } \\
\text { the Difference }\end{array}$}} \\
\hline & \multirow[t]{2}{*}{$t$} & & & & & & \\
\hline & & & & & & Lower & Upper \\
\hline & 14.179 & 28 & .000 & 16.67 & 1.18 & 14.26 & 19.07 \\
\hline & 14.179 & 19.144 & .000 & 16.67 & 1.18 & 14.21 & 19.13 \\
\hline
\end{tabular}

Table 5 shows the group statistics for the rate of switching in intermediate group for difficult task $(\mathrm{M}=22.47$, $\mathrm{SD}=4.17)$ and in easy task $(\mathrm{M}=12.13, \mathrm{SD}=3.09)$. Table 6 shows the results of one-sample T-test for both groups. As table 6 shows the $\mathrm{T}$ observed for the intermediate difficult task switches is 20.854 and this number for the intermediate easy task switches is 15.204 . corresponding the critical $\mathrm{T}$ value, the observed $\mathrm{T}$ in both tasks is significant at all the levels . Tobs $=20.854,15.204, \mathrm{df}=14, \mathrm{P}<0.001$

TABLE 5.

GROUP STATISTICS

\begin{tabular}{|lllll|}
\hline & $\mathrm{N}$ & Mean & Std. Deviation & Std. Error Mean \\
\hline Intermediate difficult task switches & 15 & 22.47 & 4.17 & 1.08 \\
\hline Intermediate easy task switches & 15 & 12.13 & 3.09 & .80 \\
\hline
\end{tabular}

TABLE 6.

ONE-SAMPLE TEST FOR DIFFICULT AND EASY TASK SWITCHES IN INTERMEDIATE GROUP.

\begin{tabular}{|c|c|c|c|c|c|c|}
\hline & Test Value $=0$ & \multirow{3}{*}{ df } & \multirow{3}{*}{ Sig. (2-tailed) } & \multirow{3}{*}{ Mean Difference } & \multirow{2}{*}{\multicolumn{2}{|c|}{$\begin{array}{l}95 \% \text { Confidence Interval of the } \\
\text { Difference }\end{array}$}} \\
\hline & \multirow[t]{2}{*}{$\mathrm{t}$} & & & & & \\
\hline & & & & & Lower & Upper \\
\hline Intermediate difficult task switches & 20.854 & 14 & .000 & 22.47 & 20.16 & 24.78 \\
\hline Intermediate easy task switches & 15.204 & 14 & .000 & 12.13 & 10.42 & 13.84 \\
\hline
\end{tabular}

Table 7 shows the group statistics for the rate of switching in advanced group for difficult task $(M=5.80, S D=1.82)$ and in easy task $(\mathrm{M}=2.27, \mathrm{SD}=1.33)$. Table 6 shows the results of one-sample T-test for both groups.As for the switches in the advanced group another within group T-test was conducted. In table 8 the related data are presented. As the table 8 illustrates the T observed for the advanced difficult task switches is 12.339 and the same number for the 
advanced easy task switches is 6.578. corresponding the critical $\mathrm{T}$ value table, the observed $\mathrm{T}$ in both difficult and easy tasks is significant at all levels. Tobs $=12.339,6.578, \mathrm{df}=14, \mathrm{P}<0.001$

TABLE 7.

GROUP STATISTICS.

\begin{tabular}{|lllll|}
\hline & $\mathrm{N}$ & Mean & Std. Deviation & Std. Error Mean \\
\hline Advanced difficult task & 15 & 5.80 & 1.82 & .47 \\
\hline Advanced easy task & 15 & 2.27 & 1.33 & .34 \\
\hline
\end{tabular}

TABLE 8.

ONE-SAMPLE TEST FOR DIFFICULT AND EASY TASKS IN ADVANCED GROUP.

\begin{tabular}{|c|c|c|c|c|c|c|}
\hline & \multirow{3}{*}{$\begin{array}{l}\text { Test Value }=0 \\
\mathrm{t}\end{array}$} & \multirow{3}{*}{ Df } & \multirow{3}{*}{ Sig. (2-tailed) } & \multirow{3}{*}{ Mean Difference } & \multirow{2}{*}{\multicolumn{2}{|c|}{$\begin{array}{l}95 \% \text { Confidence Interval of the } \\
\text { Difference }\end{array}$}} \\
\hline & & & & & & \\
\hline & & & & & Lower & Upper \\
\hline Advanced difficult task & 12.339 & 14 & .000 & 5.80 & 4.79 & 6.81 \\
\hline Advanced easy task & 6.578 & 14 & .000 & 2.27 & 1.53 & 3.01 \\
\hline
\end{tabular}

The present study was an attempt to find an answer to the questions below. In the following, the findings of the study with regard to the research questions will be discussed.

Question 1: Does L2 proficiency level have any effect on the writer's rate of switching to his/her L1?

The statistical analysis of the data revealed that the students level of proficiency effects the number of times they switch to their L1. As far as switches in the easy tasks between intermediate and advanced groups were concerned, by what was gathered from data, one can see that there is a significant difference between the two groups. Intermediate group switched more than six times as much as did the advanced group in the easy task. The mean number of switches for the intermediate group was 12.13 and this number for the advanced group was 2.27.

For the number of switches between the two groups, intermediate and advanced, in the difficult task one can observe a significant difference between the two groups. Intermediate group switched more than five times as much as did the advanced group. The mean number of switches for the intermediate group was 22.47 and the mean for the advanced group was 5.80 .

The results of the T-test within the groups also showed a significant difference. The mean difference between the easy task and difficult task within the advanced group was significant. The mean number of switches for the easy task within the advanced group was 2.27 and the mean number of switches for the difficult task within the advanced group was 5.80. The mean difference in the number of switches between the easy and difficult task in the intermediate group was also significant. The mean for the easy task was 12.13 and the mean for the difficult task in the intermediate group was 22.47. So we can state that there was difference between the two groups and learners' level of L2 proficiency had a remarkable effect on the number of times the L2 writers switched to their L1. Therefore, the hypothesis that states L2 proficiency is effective on writer's L1 switching was retained. This is corroborated with the findings of Cummings (1989), that learners with either high or low levels of proficiency used L1 for cross-linguistic comparisons and that of Zimmerman (2000), that reported minimal L1 use by advanced learners during L2 text formulating.

Question 2. Does task level of difficulty have any effect on writer's rate of switching to his/her L1?

As the results in chapter four revealed and by computing the number of switches in both tasks one can notice that there was a significant difference between the two groups. The mean difference between the easy task in the intermediate group and easy task in the advanced group was 12.13 and 2.27 respectively. The mean difference for the difficult task in the intermediate group and difficult task in the advanced group was 22.47 and 5.80 respectively. Also the mean difference for both easy and difficult tasks within both groups was significant. This number in the intermediate group for the easy task was 12.13 and for the difficult task was 22.47. The same measurement for the easy task in the advanced group was 2.27 and 5.80 for the difficult task. So we can see that both advanced and intermediate students switched to their L1, but with degrees of difference that was observed between the two groups. Therefore, the hypothesis that states task level of difficulty effects frequency of switching to L1 was retained. The findings match with that of Jones and Tetroe (1987). They found that there was much less L1 use for easier tasks. This suggested that L-S may have been affected by task difficulty.

\section{CONCLUSIONS AND IMPLICATIONS}

The data suggest that language-switching in addition to the use of L2 makes it possible for a thought to be developed cross-linguistically without slowing down the pace of thinking. It also compensates for the possible failure to produce effective output in L2 only. In other words, code-switching enabled an initiated thought to continue to develop and helped generate content which the participant sometimes felt less competent to produce when they used L2 only. This phenomenon suggests that developing a thought in an L2 at a normal speed would also be cognitively demanding

Previous research on bilingual memory structures has suggested that L2 proficiency determines bilingual memory organization and is therefore able to predict in what language a concept might best be accessed by a bilingual person (de Groot \& Hoeks, 1995). This case study suggests that the demands of a task may also be important in determining the choice of a concept access method and may help predict the language a bilingual person will use for cognitive 
processing in the context of L2 composing. As shown in this study, the extent of language-switching varies between tasks with different levels of knowledge demands. The higher the general level of knowledge demands a task had the more language-switching the participant was inclined to use as an explicit or implicit problem-solving strategy in handling the task.

The examples in the previous section demonstrate that language-switching facilitates rather than inhibits L2 composing processes. The effectiveness of language-switching provides important evidence supporting the notion that conceptual knowledge is shared across L1 and L2 and may be accessed cross-linguistically without the risk of affecting the quality at a conceptual processing level. In other words, knowledge may well be tied to a shared rather than a separate conceptual store in a bilingual's memory. These findings also suggest that further research will be needed to investigate the claim of the factor of topic knowledge in L2 composing (Friedlander, 1990).

One implication gathered from this and used for language pedagogy is that teachers should encourage the use of more switching because it can increase the quality of texts especially for the intermediate students. One more point is to encourage the use of more rehearsal and editing strategies because in addition to the general switching behavior that was evident in this research, students used some other strategies, to name a few, editing and rehearsal. But because of the complexity and limitations these two factors were not given much credit.

In the literature on L2 writing processes, much has been made of the similarities between writing in one's native language and writing in a second language. The most salient qualitative difference is that in L2 writing, two languages can be work at the same time. This is not just a matter of more or less of something; it is a different experience altogether. Considering the amount of switches in this study, one might tend to dismiss L-S as incidental. Yet we should recognize that L1 use may not have always been vocalized. Furthermore, the effect of L-S may be disproportionate to the quantity of L-S. One brief switch to the L1, for example, may be sufficient for redirecting the writer's focus.

The results of this study suggest that C-S can be beneficial. Second language writing instructors may find ways to incorporate the strategic use of this behavior into the classroom, However, further experimental studies are needed to confirm the effects of strategic C-S on L2 text length and quality. In addition, studies that focus on actual classroombased writing would be appropriate. Further studies using different language groups and different language contexts for C-S are also warranted.

Code-switching in L2 writing is probably influenced by individual factors not considered in this study, such as motivation and learning style differences. As suggested by Hayes (1996), these factors are important sources of variance in writing processes models, and future studies might address C-S in L2 writing with these factors in mind.

As for the wider implications of this study, it is possible that L-S itself, whatever its causes are, may be a kind of direct, on-line index to the developing L2 writer, in contrast to off-line and off-task measures like L2 proficiency and L1 writing skill. A developmental index measured by C-S would be consistent with socio-cultural models of language development, in which "private speech" is seen as a mental tool for difficult, non-automated tasks (Vygotsky, 1778). In this regard, L-S may be driven by the mental operations of private speech for solving L2 problems with L1 resources. This function of C-S is also compatible with a heuristic role, that of discovering and refining plans for the evolving L2 text, as suggested by Cumming (1989) and Manchon et al. (2000).

If C-S is useful for representing the development of L2 writing skills, as opposed to merely describing L2 writing processes, then one might envision C-S super-imposed on descriptive L1 (Hayes \& Flower, 1981) or L2 (Matsuda, 1997) writing models. In such a developmental model of L2 writing, C-S would diminish for lower level operations (like editing and transcribing, including word generation) as L2 proficiency increases in the face of cognitive difficulty for higher-level operations (like planning and reviewing). Such a model would encourage teachers and learners alike to remember that the $\mathrm{L} 1$ is an important resource for $\mathrm{L} 2$ writer.

\section{REFERENCES}

[1] Anton, M. \& DiCammila, F. (1998). Socio-cognitive functions of L1 collaborative interaction in the L2 classroom. The Canadian Modern language reviews, 54, 314-342.

[2] Bereiter, C. \& Scardamalia, M. (1987). The psychology of written composition. Hillsdale, NJ: Lawrence Erlbaum Associates.

[3] Berman, R. (1994). Learners' transfer of writing skills between languages. TESL Canada journal, 12, 29-46.

[4] Bialystok, E. (1990). Communication strategies: A psychological analysis of second language use. Oxford: Blackwell.

[5] Brice, A. (2000). Code switching and code mixing in the ESL classroom: A study of pragmatic and syntactic features. Advances in Speech Language Pathology. Journal of the Speech Pathology Association of Australia, 20(1), 19-28.

[6] Cumming, A. (1989). Writing expertise and second language proficiency. Language Learning, 39, 81-141.

[7] Cumming, A. (1990) Meta-linguistic and ideational thinking in second language composing. Written communication, 7, 482511.

[8] De Groot, A.M.B., \& Hoeks, J.C.J. (1995). The development of bilingual memory: Evidence from word translation by trilinguals. Language learning, 45:4, 683-724.

[9] Edelsky, C. (1982). Writing in a bilingual program: The relation of L1 and L2 texts. TESOL Quarterly, 16, 211-228.

[10] Faerch, C. \& Kasper, G. (1983). Strategies in Inter-language Communication. London. Longman.

[11] Flower, L. \& Hayes, J. (1981). A cognitive process theory of writing. College Composition and Communication, 32, 365-387.

[12] Friedlander, A. (1990). Composing in English: Effects of a first language on writing in English as a second language. In B. Kroll (Ed.), Second language writing: Research insights for the classroom. (pp. 109-125). Cambridge: Cambridge University Press. 
[13] Grosjean, R. (1987). On the methodological basis of introspective methods. In C. Færch \& G. Kasper (Eds.), Introspection in second language (pp. 54-81). Clevedon, UK: Multilingual Matters Ltd.

[14] Hayes, J. R. (1996) A new framework for understanding cognition and affect in writing. In C.M. Levy \& S. Randsdell (Eds.), The science of writing: theories, methods, individual differences, and applications (pp. 1-27), Mahwah, NJ: Erlbaum.

[15] Heller, M. (Ed.) (1988). Codes-witching: Anthropological and sociolinguistic perspectives. Berlin: Mouton de Gruyter.

[16] Hull, G. (1985). Research on error and correction. In B. McClelland \& T. Donovan (Ed.), perspective on research \& scholarship in composition (pp. 162-184). New York: The Modern Language Association of America.

[17] Jones, C.S., \& Tetroe, J. (1987). Composing in a second language. In A. Matsuhashi (Ed.), Writing in real time: Modelling the production processes (pp. 34-57). Newark, NJ: Ablex.

[18] Kobayashi, H., \& Rinnert, C. (1992). Effects of first language on second language writing: Translation versus direct composition. Language Learning, 42, 183-215.

[19] Manchon, R., Roca de larios, J., \& Murphy, L. (2000). An approximation to the study of backtracking in L2 writing. Learning and Instruction, 10, 13-35.

[20] Matsuda, P. (1997). Contrastive rhetoric in context: a dynamic model of L2 writing. Journal of second language writing. 6, 4560.

[21] Milroy, L \& Muysken, P. (eds.) (1995). One speaker, two languages: cross-disciplinary perspectives on code-switching. Cambridge: Cambridge University Press.

[22] Oi, M.K. (1984): Cross-cultural differences in rhetorical patterning: A study of Japanese and English. Dissertation Abstracts International, 45(8), 2511A.

[23] Qi, D. (1998) An inquiry into language switching in second language composing process. The Canadian Modern Language Review. 54/3: 413-435.

[24] Silva, T. (1993). Toward an understanding of the distinct nature of L2 writing: The ESL research and its implications. TESOL Quarterly, 27, 657-677.

[25] Tamamaki, K. (1993). Language dominance in bilinguals' arithmetic, 43,239-262.

[26] Uzawa, K. (1996): Second Language Learners` Processes of L1 Writing, L2 Writing, and Translation from L1 into L2. Journal of Second Language Writing, 5 (3), pp. 271-294.

[27] Vygotsky, L. S. (1978). Mind in Society: The Development of Higher Psychological Processes, Trans. \& Ed. by Cole, M., John-Steiner, J., Scribner, S., \& Souberman, E. (1978). Harvard University Press: Cambridge, MA.

[28] Walen, K., \& Menard, N. (1995). L1 and L2 writers' strategic and linguistic knowledge: a model of multiple-level discourse processing. Language learning, 45,381-418.

[29] Woodall, B. (2000). Language-switching in second language writing. Unpublished doctoral dissertation, University of Washington, Seattle, WA.

[30] Zamel, V. (1983): The composing processes of advanced ESL students: Six case studies. TESOL Quarterly 17:165-187.

[31] Zimmerman, R. (2000). L2 writing: sub-processes, a model of formulating and empirical findings. Learning and Instruction, 10, 73-99.

Amir Sabzevar Qahfarokhi is currently a PhD candidate in Teaching English as a Foreign Language in Islamic Azad University, Khorasgan Branch. He is also a faculty member at Islamic Azad University, Shahrekord Branch, Iran. He has participated in international conferences such as WCCES. His areas of interest include Discourse analysis, Critical discourse analysis, and second language writing.

Reza Biria currently works as an Assistant Professor at Khorasgan Azad University, Isfahan. His research interests include teaching English as a second and foreign language, advanced research and ESP. He has also published at different national and international journals. 